\section{Endoscopic Diagnosis of Retrograde Jejunojejunal Intussusception}

We reported here a case of postgastrectomy retrograde jejunojejunal intussusception in a patient with coffee-ground vomiting. The diagnosis was correctly made at endoscopy, and confirmed with contrast examination.

A 73-year-old man was admitted with acute onset of coffee-ground vomiting. He had undergone Polya gastrectomy eight years previously for upper gastrointestinal bleeding. At endoscopy, jejunojejunal intussusception was noted in the efferent limb; the jejunal mucosa was edematous (Figure 1). Water-soluble contrast was then injected via the endoscope. There was a "claw sign", with contrast stopping abruptly at the intussusceptum (Figure 2). At emergency laparotomy, the intussusception was reduced, and a nonviable segment of the jejunum was resected. Bowel continuity was restored with primary small-bowel anastomosis. The patient's recovery was uneventful. Pathologic examination of the resected jejunum did not reveal any cause for the intussusception.

Jejunojejunal intussusception is a rare complication after gastric surgery. It can present as an acute fulminant type, or a chronic relapsing type. Endoscopic diagnosis of the condition has been well described $(I-3)$, and endoscopic reduction of jejunojejunal intussusception has been reported in a single case (4). The present case confirms that the diagnosis can be made at endoscopy. The role of endoscopic reduction, however, remains unproved. Due to the chronic relapsing nature of the condition and the subsequent risk of incarceration of the intussusceptum, surgery should be the primary treatment $(5)$.

\section{References}

1. Brown JW: Retrograde jejunogastric intussusception confirmed pre-operatively by gastroscopy. Gastrointest Endosc 1970; 17: $70-1$.

2. Domjan L, Baltas B. Chronic recurrent jejunogastric intussusception diagnosed by gastroscopy. Endoscopy 1975; 7: 105-8.

3. Ertresvaag K, Haffnur JFW. Jejunogastric intussusception, an acute exacerbation diagnosed by gastroscopy. Endoscopy 1981; 13: $131-3$

4. Kochhar R, Saxena R, Nagi B, et al. Endoscopic management of retrograde jejunogastric intussusception. Gastrointest Endosc 1988; 34: 56-7.

5. Czerniak A, Bass A, Bat L, et al. Jejunogastric intussusception. Arch Surg 1987: 122: 1191-2.

\section{W. H. Lee, J. Y. W. Lau, A. C. W. Chan, S. C. S. Chung,} A. K. C. Li

Dept. of Surgery, Chinese University of Hong Kong. Prince of Wales Hospital, Hong Kong

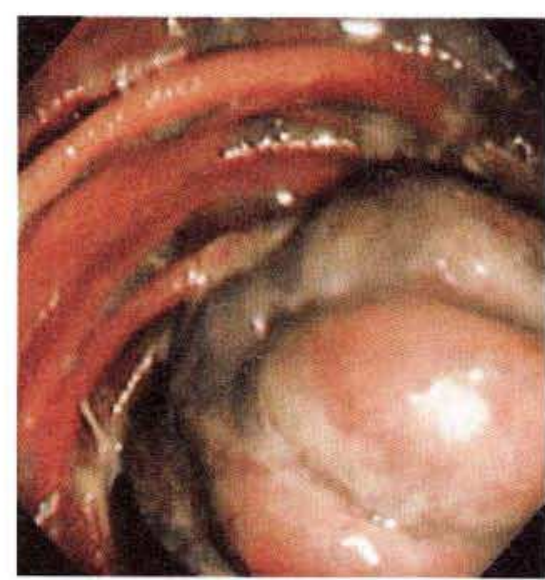

Figure 1: Endoscopic view of the jejunojejunal intussusception.

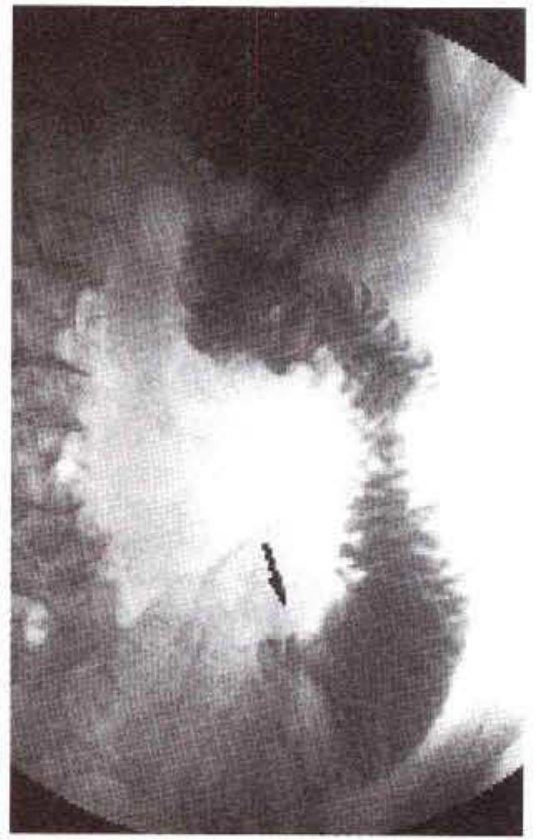

Figure 2: Contrast study showing the "daw sign" (arrow).

Corresponding Author

A. K. C. Li, M.D.

Dept. of Surgery

Chinese University of Hong Kong

Prince of Wales Hospital

Shatin

Hong Kong

Fax: $+852-26370979$ 